\title{
Research and Realisation of High-Power Medium Voltage Active Rectifier Concepts for Future Hybrid-Electric Aircraft Generation
}

\author{
A. Trentin, G. Sala, L. Tarisciotti, Member, A. Galassini, Member, M. Degano, Member, P. H. Connor, \\ D. Golovanov, Member, D. Gerada, Member, Z. Xu, Member, A. La Rocca, C. N. Eastwick, S. J. Pickering, \\ P. Wheeler, Senior Member, J. C. Clare, Senior Member, and C. Gerada, Senior Member
}

\begin{abstract}
This paper describes the research and development of a $3 \mathrm{kV}$ active rectifier for a $4 \mathrm{MW}$ aerospace generator drive system demonstrator. The converter is fed by a multi-phase high speed/high frequency, permanent magnet generator. The main aim of the work is to demonstrate for the first time the feasibility of a MW-class generator system meeting future hybrid-electric propulsion requirements. A concept with multiple and isolated threephase systems feeding different power buses is proposed to meet the availability requirements. Multiple converters (one for each three-phase system) are connected in series and/or in parallel to achieve the rated power and DC link voltage. This paper describes the key design concepts and the development and testing of the converter to meet the challenging application requirements. Reduced power tests are carried out on a full scale $4 \mathrm{MW}$ converter prototype, validating the proposed design. The work represents a step forward in terms of voltage, power, and output frequency, with respect to the state of the art.
\end{abstract}

Index Terms-Hybrid Electric Aircraft, High-Power Generation Systems, High-Power High-Voltage Converter Design, Multiphase Drives, Aerospace Generation Drives, Variable Speed Drives.

\section{INTRODUCTION}

$\mathrm{I}_{\mathrm{a}}^{\mathrm{N}}$ $\mathrm{N}$ the past two decades, all the major stakeholders in the aviation industry have been working to define aircraft technology roadmaps for the reduction of net carbon emissions [1]. In Europe, the vision for sustainable aviation set by the Flightpath 2050 program targets a reduction of $\mathrm{CO}_{2}$ emissions per passenger kilometer of $75 \%$ and $\mathrm{NO}_{\mathrm{x}}$ of $90 \%$, compared to the 2000 figures [2], [3]. Within the Environmentally Responsible Aviation (ERA) framework, NASA has set equivalent goals and timescales, to reduce both fuel burn by $50 \%$, as well as NOx emissions by $75 \%$ [4].

A. Trentin, G. Sala, A. Galassini, M. Degano, P. H. Connor, D. Golovanov, D. Gerada, Z. Xu, A. La Rocca, P. Wheeler, J. C. Clare, C. Gerada are with the Department of Electrical and Electronic Engineering, The University of Nottingham, Nottingham, NG7 2RD, U.K. (e-mail: michele.degano@nottingham.ac.uk).

L. Tarisciotti is with the Universidad Andres Bello, Santiago, 7550196, Chile (e-mail: luca.tarisciotti@unab.cl).

G. Sala is with the Department of Electric, Electronic and Information Engineering "G. Marconi," University of Bologna, 40126 Bologna, Italy (email: giacomo.sala5@unibo.it).

C. N. Eastwick and S. J. Pickering are with the Department of Mechanical, Material and Manufacturing Engineering, University of Nottingham, NG7 2RD, U.K.
A number of programs have led to the development of concepts for a new generation of future air vehicles which are ever-more efficient, environmentally friendly and quiet [5], [6]. These developments are all aiming at reducing the fuel consumption and have a strong direct socio-economic and environmental impact [7]. The programs mentioned above are tackling the problem from varying angles, for example trying to improve combustion technologies and/or to look for new disruptive technologies leading towards electric and hybrid-electric solutions. Full electric propulsion systems are not yet able to replace the conventional fuel engines [8]. However, thanks to the on-going development of power electronics, hybrid-electric solutions already have the potential to revolutionize aircraft propulsion and generation systems, as well as the aircraft design. A hybrid-electric propulsion system combines the advantages of fuel-based and battery powered systems and offers new design freedoms [9].

Among all the passenger aircraft, the 50 to 150 seat regional aircraft are considered as suitable candidates for this first shortto-medium term transition, and key companies have put together joint efforts in the attempt to boost the development of this technology [1]. A clear example is the E-Fan X demonstrator, which is a collaboration between Rolls-Royce and Airbus for the development of a hybrid-electric propulsion system [10]. This activity was aimed at replacing one of the 4 traditional propulsion gas turbines with a $2 \mathrm{MW}$ electric drive, supplied from a $2 \mathrm{MW}$ generator driven by a gas turbine in the fuselage [11]. Other programs, that have seen the involvement of international consortia, comprising industrial, research and academic institutes, are moving towards the same goal in exploring revolutionary aircraft technologies [12]. Among these, Boeing and JetBlue in the Zunum Aero program, are targeting the development of a hybrid-electric passenger aircraft with $10-50$ seats [13].

Within this context, there is a critical need for reliable electric drive architectures with high power and voltage with reduced mass and volume [14]-[16]. A typical concept for a hybrid turbo-electric layout is shown in the schematic in Fig. 1. Starting from the left-hand side, a gas turbine (T) drives an electrical generator $(\mathrm{G})$ connected to an AC/DC converter, with two separate isolated output channels (here called BRAVO and ECHO). Each channel supplies different power buses each of which provides power to its propulsion motor(s) (M), through a DC/AC converter, and is interfaced to an energy storage system (battery) through DC/DC converters. 


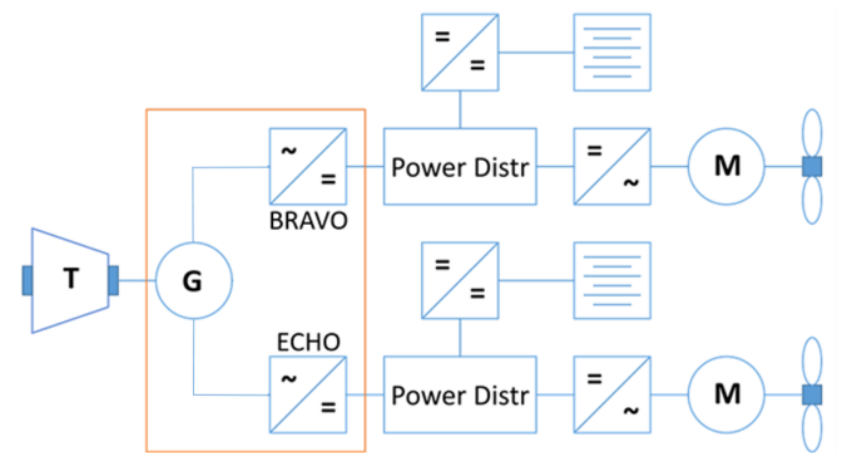

Fig. 1: Schematic of the drive train system. The subsystem considered within this project is the one highlighted in the orange box: where $G$ is the electrical machine (Generator) and where BRAVO and ECHO are two channels of the converter.

Once the architecture of the power system is defined, enabling hybrid-electric aircraft flight with state-of-the-art component technology requires the power density of the electric drive to be pushed to its physical limits [6]. In fact, the expectations for on-board power generation have rapidly increased thanks to more reliable power electronics and drives with higher voltage levels [16], and the transition from $270 \mathrm{~V}$ to $540 \mathrm{~V}$ DC is now considered to be the norm. However, higher voltage systems, such as MVDC/HVDC, must be adopted when the power density of the drive needs to be further increased [17], [18]. Together with the voltage increase, it is usually preferred to have direct coupling between the gas turbine and the generator in order to remove the volume and mass of the gearbox, and the related probability of failure [15], [19]. As a result, direct drive generators normally need to operate at a speed in the range of tens of krpm, to give the lowest mass of the gas turbine-generator set [20].

Increasing the speed of generators increases the power density of the electrical machine. However, producing large power at high voltage and speed introduces significant challenges from many points of view, such as: increased insulation and power rating of each component; introduction of rotor dynamics and mechanical stresses due to generator and turbine interactions; increased fundamental frequency with consequent increase of $\mathrm{AC}$ losses in the generator; increased loss density requiring more intensive cooling systems for both the converter and electrical machine. The achievable power and power density and reliability/availability of the drive are limited by state-of-the-art technologies.

Many of these limitations can be mitigated, especially when high power density and fault tolerance is required through the use of multiple 3-phase or multiphase sets of windings [21]. In the literature, a wide range of multiphase electrical machine designs have been proposed to improve system power density in applications such as high power turbo compressors [22], electric ship propulsion [23]-[25], and other safety critical applications [14]. The key advantages of a multiphase solution can be summarized as a split of the machine power among a higher number of phases, flexibility in terms of architecture layout, and more importantly for aerospace applications, increased availability [26].

Similarly, to enable the use of lower voltage rated devices, power electronics can be designed using multilevel converter topologies. Although series (cascade) connected switching devices may be considered as an alternative, their use reduces the maximum switching frequency and the efficiency of the converter [27]-[29]. Therefore, multilevel converter topologies are often applied to MV and HV 3-phase drives [30]. The main disadvantage of multilevel converters is the increased number of components and, thus, lower power density with respect to simpler topologies. However, this issue can be addressed by an optimized converter design for the specific application, with Neutral Point Clamped (NPC) and Cascaded H-Bridge (CHB) converters being particularly considered for drive applications [31]. The NPC converter is a 3-level converter with a structure that requires active balancing of its two DC-link capacitors, and it is difficult to scale to higher number of levels [32], [33].

By taking advantage of a multiphase electrical machine architecture, it is also possible to combine the advantages of the NPC and CHB converter topologies to achieve a multiphase and multilevel drive architecture. In fact, in a multi 3-phase drive, the flexibility of the architecture allows the assembly of multiple three-phase converters in series and parallel layouts.

This work presents and demonstrates the challenges in developing a $4 \mathrm{MW}$ (5MVA), $3 \mathrm{kV}$, high power-density drive, suitable for the future on-board generating systems of hybridelectric aircraft. The paper presents an architecture of a highpower medium-voltage drive, featuring a high-speed multiphase machine with a permanent magnet rotor and multiple isolated three-phase windings in the stator. In this paper, the converter structure is designed with a cascade and parallel architecture of NPC submodules, and the design choices are described in detail. This demonstrates that, with the current state-of-the-art component technology, a high powerdensity drive for future hybrid-electric platforms can be achieved with innovative approaches to the architecture.

The research contributions of this work can be summarised as follows: 1) for the electrical machine design adopted, a feasibility analysis for different candidate converter structures and devices is performed; 2) based on the selected topology, a control scheme which combines several control operating modes and voltage balancing systems is designed to address the specific requirements of the converter and application; 3) a full scale prototype has been constructed and tested, thus validating the control approach and design as well as providing efficiency measurements for the full generation system.

\section{High LeVel Converter Design}

The three main parameters which need to be considered when designing a medium voltage aircraft DC generation system are:

1. The electrical machine nominal speed and, therefore, its fundamental electrical frequency. In the case considered, it is set to $1 \mathrm{kHz}$.

2. The DC link nominal voltage. For this development, the requirement is to have two independent $\mathrm{DC}$ output ports, i.e., two isolated DC-links each with a DC voltage of $3 \mathrm{kV}$.

3. The nominal power of the system, in this case $4 \mathrm{MW}$ (5MVA) was targeted. 
It is important to highlight that the design decisions are also affected by the generator design. Although the paper focuses on the power electronic conversion system, information about the generator is given in Appendix A.

\section{A. Device and operating switching frequency selection}

As already demonstrated in previous work [45] the converter switching frequency should be at least 10 times higher than the fundamental frequency. Thus, considering the generator fundamental frequency of $1 \mathrm{kHz}$, the minimum switching frequency for the power conversion system is equal to $10 \mathrm{kHz}$. However, a further increase in the switching frequency benefits the converter operation by reducing the phase current ripple and the output voltage low frequency harmonic content as well as increasing the current controller bandwidth that is obtainable. The benefits of increasing the switching frequency are even more pronounced when dealing with a high power, high efficiency generator, which presents a small value of leakage inductance. On the other hand, increasing the switching frequency also increases the switching losses limiting the selection of power devices. For these reasons, the switching frequency has been set at a trade-off value of $15 \mathrm{kHz}$, where both SiC MOSFETs and traditional Si IGBTs, rated at $1.2 \mathrm{kV}$, are viable options. Higher voltage rating IGBTs are unlikely to perform adequately at a switching frequency of $15 \mathrm{kHz}$. For example, $\mathrm{Si}$ IGBTs rated are $3.3 \mathrm{kV}$ are intended for applications where the maximum switching frequency is in the range of $2-3 \mathrm{kHz}$ [34], [35].

Similarly, $1.7 \mathrm{kV} \mathrm{SiC} \mathrm{MOSFETs} \mathrm{are} \mathrm{still} \mathrm{rarely} \mathrm{used} \mathrm{due} \mathrm{to}$ procurement issues and $\mathrm{SiC}$ devices for voltages higher than $1.7 \mathrm{kV}$ are not yet commercially available.

\section{B. Converter architecture}

To work within the limitations of the power devices, various converter architectures can be considered. In this paper, only two and three level NPC I-type converters are considered. The reason for this choice is mainly due to manufacturer availability and lead-time for the related power modules.

The 3-Level NPC T-type converter, which presents a better efficiency than other topologies, has been discarded as it does not allow the use of lower voltage rated devices [36]. Also, the 3-Level active NPC have been excluded because of the high number of devices per leg. Similarly, more complex layouts with series connected devices have not been considered since the available switching frequency is reduced, owing to the parasitic components in the commutation circuit, which could lead to possible overvoltage stress of the device die [37].

In conclusion, $1.2 \mathrm{kV}$ devices are considered in this work. For these devices, the typical DC-link voltage for an active front end is $700-750 \mathrm{~V}$ (using a 2-level converter). Therefore, to meet the specification of a $3 \mathrm{kV}$ DC voltage by using only 2 and 3level converters as building blocks, a number $\left(\mathrm{N}_{\mathrm{s}}\right)$ of these converters must be connected in series.

If 2-level converters are connected in series, four modules are needed to sustain a DC voltage of $3 \mathrm{kV}$. Whereas, only two converters in series are sufficient if 3-level I-type power modules are considered. In fact, the 3-level I-type topology features an inherent voltage sharing capability which makes the converter able to sustain a DC-link of $1.5 \mathrm{kV}$, halving the required number of series converters.

\section{Selection of the optimal number of phases}

The final consideration is the nominal power of the conversion system. In this specific case, the converter is required to convert a power of $4 \mathrm{MW}$ that is generated from an electrical machine, which has a Power Factor (PF) of 0.8 , resulting in an apparent power of 5MVA. From this data it is straightforward to calculate the nominal power of each single converter, once the number of series $\left(\mathrm{N}_{\mathrm{s}}\right)$ and parallel $\left(\mathrm{N}_{\mathrm{p}}\right)$ power modules is defined. The total number of converter cells is $\mathrm{N}_{\mathrm{t}}=\mathrm{N}_{\mathrm{s}} \mathrm{N}_{\mathrm{p}}$ ), and the total number of phases of the multi threephase electrical machine is $\mathrm{N}_{\mathrm{ph}}=3 \mathrm{~N}_{\mathrm{t}}$.

In order to establish the output voltage of each cell, the maximum modulation index is set to $95 \%$ for the 2-Level solution, whereas for the 3 -Level it is set to $80 \%$ to take into account some margin for the internal voltage balancing. At this point, the rms phase current is evaluated from the power of each cell $\left(5 \mathrm{MVA} / \mathrm{N}_{\mathrm{t}}\right)$. Once the rms phase current is calculated, it is possible to estimate the rated current of the power module (the typical value at a temperature of $25^{\circ} \mathrm{C}$ ), by doubling the phase current. However, considering the relatively high switching frequency, the high power, and the complex converter layout, the rated current of the Si IGBTs power modules is considered 3 times the phase current for safety margin. If SiC MOSFETS are used, this can be reduce to 2 times the phase current because of the lower switching losses [38].

\section{Summary}

As a final remark, it must be considered that a higher number of cells results in a more complex electrical machine and converter design, in terms of sensors, gate drives and control. Ideally, the best solution is the one that minimizes the number of cells whilst respecting the device capabilities.

TABLE I

THE SINGLE CELL POWER, PHASE CURRENT AND VOLTAGE (RMS VALUES) FOR DIFFERENT CONFIGURATIONS USING A 2-LEVEL CONVERTER

\begin{tabular}{ccccccccc}
\hline \hline $\mathrm{N}_{\mathrm{s}}$ & $\mathrm{N}_{\mathrm{p}}$ & $\mathrm{N}_{\mathrm{t}}$ & $\begin{array}{c}\mathrm{N}_{\mathrm{p}} \\
\mathrm{h}\end{array}$ & $\begin{array}{c}\text { Cell } \\
\text { Power } \\
{[\mathrm{VA}]}\end{array}$ & $\begin{array}{c}\text { Phase } \\
\text { Voltage } \\
\text { [Vrms] }\end{array}$ & $\begin{array}{c}\text { Phase } \\
\text { Current } \\
\text { [Arms] }\end{array}$ & $\begin{array}{c}\text { SiC } \\
\text { current } \\
\text { rating } \\
{[\mathrm{A}]}\end{array}$ & $\begin{array}{c}\mathrm{Si} \\
\text { current } \\
\text { rating } \\
{[\mathrm{A}]}\end{array}$ \\
\hline 4 & 2 & 8 & 24 & $\begin{array}{c}62500 \\
0\end{array}$ & 291 & 716 & 1432 & 2149 \\
$\mathbf{4}$ & $\mathbf{4}$ & $\mathbf{1 6}$ & $\mathbf{4 8}$ & $\begin{array}{c}\mathbf{3 1 2 5 0} \\
\mathbf{0}\end{array}$ & $\mathbf{2 9 1}$ & $\mathbf{3 5 8}$ & 716 & $\mathbf{1 0 4 7}$ \\
4 & 6 & 24 & 72 & $\begin{array}{c}20800 \\
0\end{array}$ & 291 & 239 & 477 & 716 \\
4 & 8 & 32 & 96 & $\begin{array}{c}15600 \\
0\end{array}$ & 291 & 179 & 358 & 537
\end{tabular}

TABLE II

THE SINGLE CELL POWER, PHASE CURRENT AND VOLTAGE (RMS VALUES) FOR DIFFERENT CONFIGURATIONS USING A 3-LEVEL CONVERTER

\begin{tabular}{ccccccccc}
\hline \hline $\mathrm{N}_{\mathrm{s}}$ & $\mathrm{N}_{\mathrm{p}}$ & $\mathrm{N}_{\mathrm{t}}$ & $\mathrm{N}_{\mathrm{ph}}$ & $\begin{array}{c}\text { Cell } \\
\text { Power } \\
\text { [VA] }\end{array}$ & $\begin{array}{c}\text { Phase } \\
\text { Voltage } \\
\text { [Vrms] }\end{array}$ & $\begin{array}{c}\text { Phase } \\
\text { Current } \\
\text { [Arms] }\end{array}$ & $\begin{array}{c}\text { SiC } \\
\text { current } \\
\text { rating } \\
{[\mathrm{A}]}\end{array}$ & $\begin{array}{c}\mathrm{Si} \\
\text { current } \\
\text { rating } \\
{[\mathrm{A}]}\end{array}$ \\
\hline 2 & 2 & 4 & 12 & 1250000 & 490 & 851 & 1700 & 2552 \\
$\mathbf{2}$ & $\mathbf{4}$ & $\mathbf{8}$ & $\mathbf{2 4}$ & $\mathbf{6 2 5 0 0 0}$ & $\mathbf{4 9 0}$ & $\mathbf{4 2 5}$ & 850 & $\mathbf{1 2 7 6}$ \\
2 & 6 & 12 & 36 & 416700 & 490 & 284 & 567 & 851 \\
2 & 8 & 16 & 48 & 312500 & 490 & 213 & 425 & 638
\end{tabular}


Looking at Table I, the configurations featuring 2-level power modules based on $\mathrm{SiC}$ MOSFETs will require a high number of converters ( 72 or 96 ), owing to the limitation of the currently commercially available devices, with current ratings up to $450 \mathrm{~A}$. For this reason, the 2-level $\mathrm{SiC}$ MOSFET modules are excluded. Conversely, market availability of 2-level power modules with Si IGBTs is high. Considering off the shelf components and assuming one power module is used per phase, there are multiple choices in terms of rated current: 450A, $600 \mathrm{~A}, 900 \mathrm{~A}, 1200 \mathrm{~A}, 1400 \mathrm{~A}, 1500 \mathrm{~A}$ and $1800 \mathrm{~A}$, respectively. The solution with the lowest number of converters is the one with four in series and four in parallel, which leads to a total of 16 modules supplying a 48-phase electrical machine. The rated current of the power module is 1200A. As a reference choice the Infineon FF1800R12IE5P could be considered. This solution is given in Table I, highlighted in bold.

In case of 3-Level I type power-modules there is a limited number of available choices. However, it is possible to find power modules with rated currents from 400A to $1800 \mathrm{~A}$ which use Si IGBT, whilst presently there are no power modules which have SiC MOSFETs for this converter structure, at least for this current range. As for the previous case, the solution with the lowest number of converters (i.e. eight modules rated at 1200A) is the preferable choice. This leads to the Vincotech 70W624N3A1K2SC-L400FP power module selection. This solution is given in Table II, highlighted in bold.

The final choice for the converter architecture was made by also considering its effect on the reliability of the system. The main drawback of using power cells connected in series is that if a single cell stops working (e.g., due to a fault detection) the full converter series needs to be disabled. Contrarily, in case of parallel cells, each cell can still operate even when one or more cells are turned off. It results that reducing the number of converters in series and increasing the number of converters in parallel is a suitable choice for the reliability of the full system, which is able to deliver more power under a fault detection in a single cell. In conclusion, the 3-level converter solution, highlighted in bold in Table II, has been selected due to the reduced number of phases $\left(\mathrm{N}_{\mathrm{ph}}=24\right)$ and the effectiveness of its redundancy, resulting from the limited number of cells in series $\left(\mathrm{N}_{\mathrm{s}}=2\right)$.

\section{Selected Converter Description}

The selected topology for this prototype is a modular multilevel and multiphase converter. Two independent DC-link channels, namely BRAVO and ECHO, are designed each with series-parallel connection of four 3-Level I-type NPC cells, as shown in Fig. 2. Pairs of NPC converters are connected in series to provide a $3 \mathrm{kV}$ DC-link. Each 3-phase NPC is connected to one of the eight star-connected 3-phase machine windings and consequently processes $0.5 \mathrm{MW}$ of power. Each channel (BRAVO or ECHO) therefore interfaces to four star-connected three-phase AC generator windings. Each NPC shown in Fig. 3(a) comprises three 3-level IGBT power modules from Vincotech (70-W624N3A1K2SC-L400FP) and two custom made DC-Link capacitors, as shown in Fig. 3(b), each of $600 \mu \mathrm{F}$.

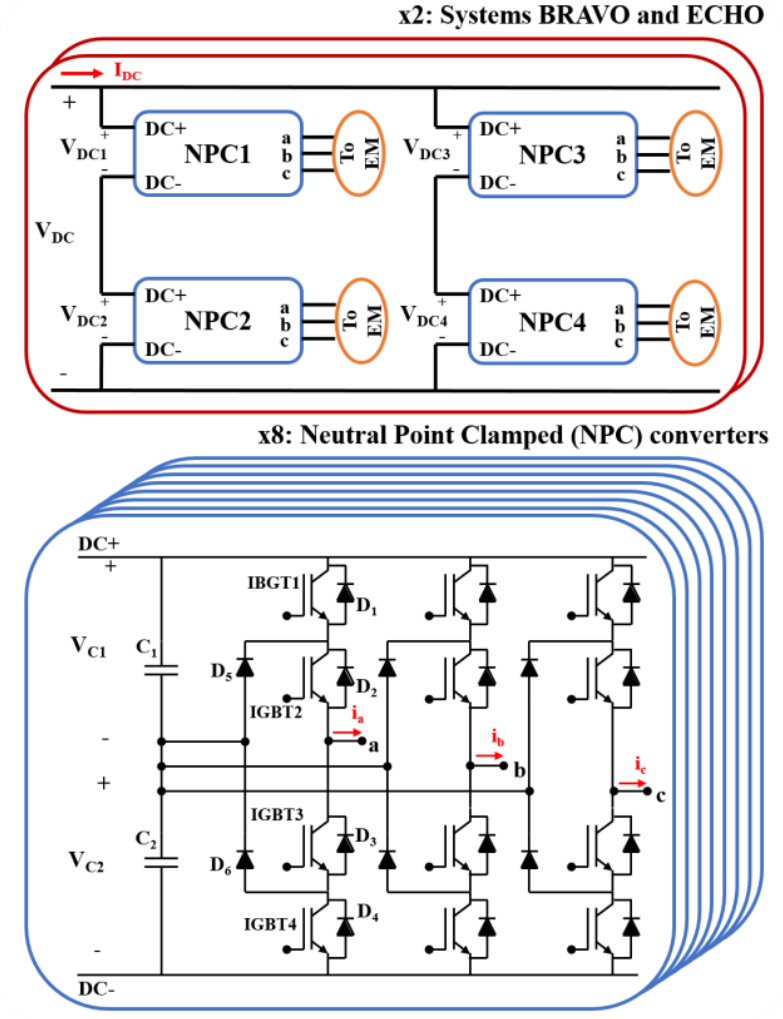

Fig. 2: Full 24-phase converter comprised of two 3kV DC-Link channels.

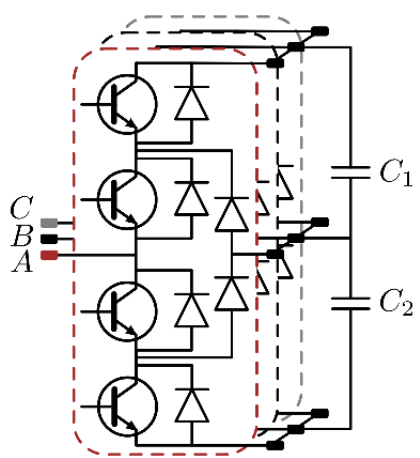

(a)

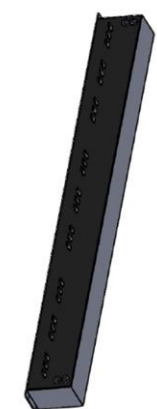

(b)
Fig. 3: (a) Three NPC power modules with DC-Link capacitors; (b) Enclosure of the DC-Link capacitors (C1 and C2).

When multiple active rectifiers are integrated in a single application, there are both design and control challenges. The control must implement balancing algorithms to maintain the voltages of all the capacitors close to the same value. Also, in the converter design, the modularity of the layout has to be carefully integrated in the overall structure as shown in Fig. 4 and Fig. 5. The power modules and the capacitors have been arranged to minimize the mass and the volume of the overall converter. The four series NPC clusters have been mechanically grouped into four layers, with the arrangement shown in Fig. 4, and stacked one on top of the other, as in Fig. 5 where the full converter prototype is shown. 


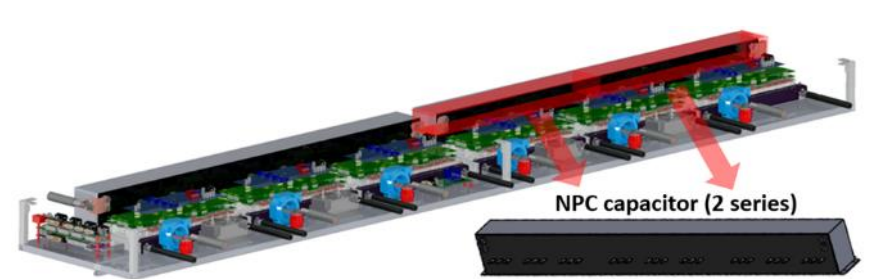

Fig. 4: Single NPC series.

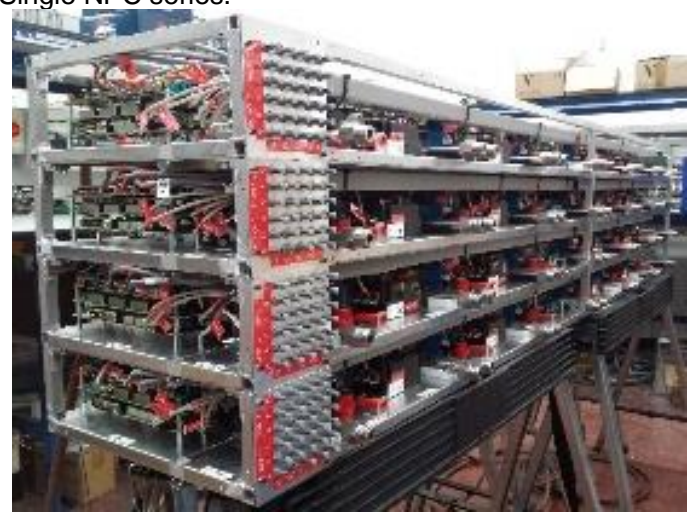

Fig. 5: The final converter structure with the four series connected NPC pairs stacked on top of each other.

The mass of the prototype converter is $240 \mathrm{~kg}$, and its volume is 411 litres, so the power density is $\sim 20.8 \mathrm{kVA} / \mathrm{kg}$ and $\sim 12 \mathrm{kVA}$ /litre. The power density is calculated using the mass of all components and the volume within the cuboid converter structure envelope, not including coolant mass. Considering that the converter is developed with commercially available $\mathrm{Si}$ IGBT technology, this is an outstanding power density, with respect to the reference values presented in the most recent developments [5], [6], [36]. To control the converter, two independent control systems are used (namely BRAVO and ECHO). These two systems are identical in their structure and they are synchronized through a serial communication with a bandwidth of $10 \mathrm{MHz}$. In this way, at every sampling instant, the two systems can exchange information about their status and all the relevant information to implement the field-oriented control. Fig. 6 shows the structure of the control hardware. Each controller employs one TMS320C6713 Digital signal processor (DSP) and two ProASIC3A3P400 fieldprogrammable gate arrays (FPGAs). Both the control systems (BRAVO and ECHO) generate 48 gate-drive signals, while monitoring the status of the gate drives receiving a discrete signal for each output phase.

Additionally, each controller has 20 independent 14-bit analogue to digital converters (ADC) that are synchronously triggered to acquire all the electrical measurements (specifically one current sensor per phase and two voltage sensors per NPC). Furthermore, each control system is capable of monitoring 24 multiplexed temperature measurements. Finally, all the reference signals for each converter are sent via a PC using a USB interface.

\section{The CONTROL DESIGN}

The overall control concept for the generator is based on a field oriented scheme [39], assuming the direct axis of the phase current aligned with the permanent magnet rotor flux.

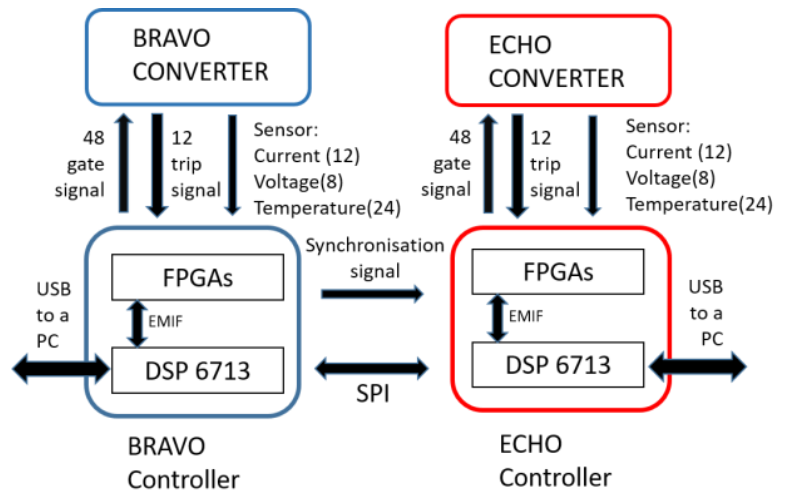

Fig. 6: The control hardware architecture.

Considering the modular (parallel and series) converter structure under investigation, the control system presents several challenges. Firstly, for each DC channel, the converter has two voltage sources connected in parallel, represented by the series connected NPC branches. Thus, it must be capable of controlling the instantaneous voltage generated by the branches to the same value, in order to avoid undesired circulating currents through the converter. Secondly, within each NPC branch, the converter must generate equal DC voltages on the series connected NPCs.

Considering these challenges, the two DC-Link channels (BRAVO or ECHO) have been with the control scheme shown in Fig 7. Each channel can be operated in different modes such as: speed control, torque control and DC link voltage control. Considering the latter, the outer control loop aims to track the reference set point for the total DC voltage of the respective channel. Similarly, when in speed mode, the outermost control loops control the speed of the shaft. The output of the outermost loop (either speed or DC link voltage) defines the reference value of the global quadrature current component, $\mathrm{I}_{\mathrm{q}, \mathrm{ref}}$. Since the application considered is in aerospace, it is vital to reduce the converter volume and weight. This means that the capacitor value must be minimized, making it challenging to passively balance the DC voltage between the series connected NPCs and within the single NPCs. This is achieved by an active DC voltage balancing algorithm, which modifies $\mathrm{I}_{\mathrm{q}, \mathrm{ref}}$ in order to maintain the DC voltages of the two series connected NPCs equal. For example, $\mathrm{V}_{\mathrm{DC} 1}$ and $\mathrm{V}_{\mathrm{DC} 2}$ in Fig. 7, should be equal. Consequently, the two NPCs of each series connection have different current references, namely $\mathrm{I}_{\mathrm{q} 1}{ }^{*}$ and $\mathrm{I}_{\mathrm{q} 2}{ }^{*}$, respectively. Finally, a current control is implemented for each NPC cell. Furthermore, the capacitor voltage balance within the single NPC is integrated in the modulation algorithm, which generates the required switching signals and, at the same time, maintains the voltage on the two inner capacitors of each NPC equal $\left(\mathrm{C}_{1}\right.$ and $\mathrm{C}_{2}$ in Fig. 3). This algorithm employs a zero-sequence voltage injection depending on the direction of the phase currents and the reference voltage of each phase. This algorithm aims to maintain the voltage of the two inner capacitors of each NPC equal, for example, $\mathrm{C} 1$ and $\mathrm{C} 2$ in Fig. 3 [40]. Fig. 8 shows the structure of the outer loops. If the system is operating in motoring mode, the speed control can be implemented as in Fig. $8(\mathrm{a})$. 
A Proportional Integral (PI) controller generates a total torque reference, which is then divided by 4 to define a torque reference for each NPC. After being limited, the torque reference is then converted to a quadrature current set point by simply implementing Eq. (1), where $k_{t}[\mathrm{Nm} / \mathrm{A}]$ is the machine torque constant. This reference current $I_{q, r e f}$ is the input to the current control loop, represented by the schematic of Fig. 9 .

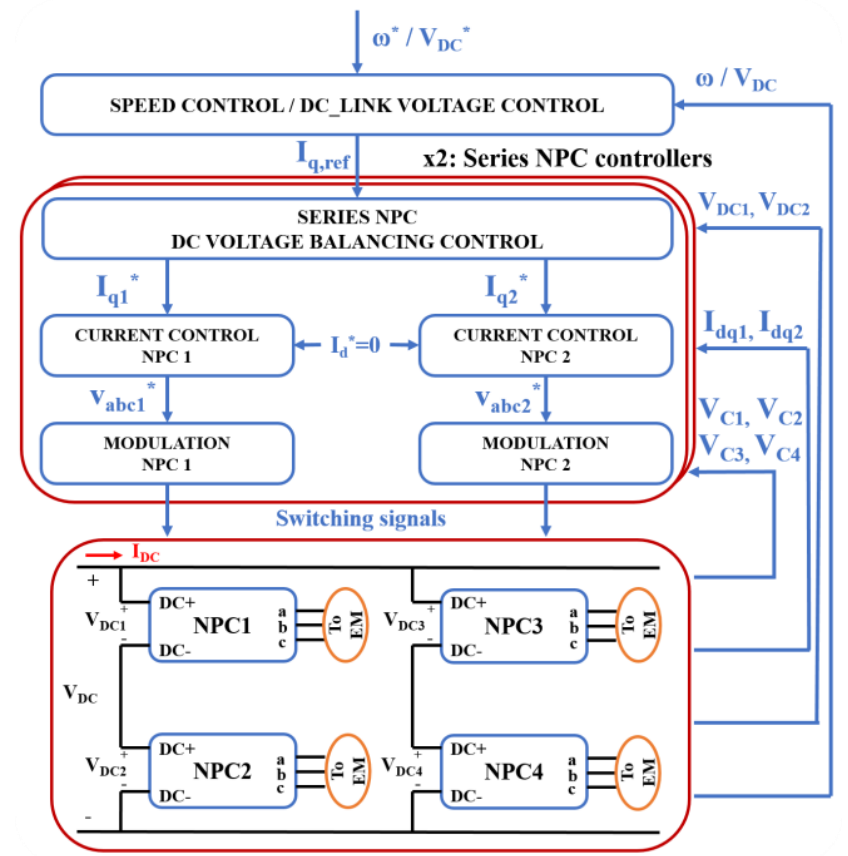

Fig. 7: The control structure for a single channel.

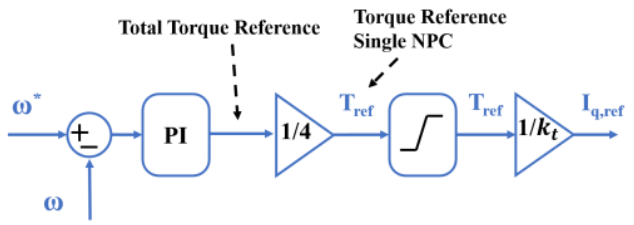

(a)

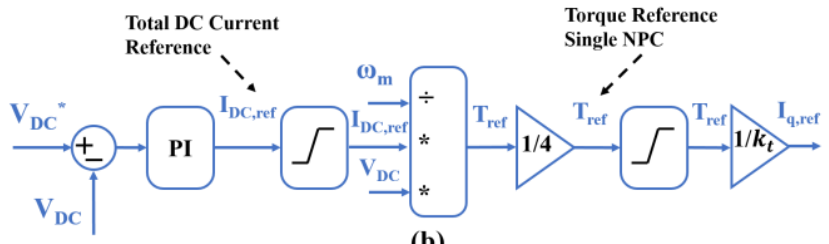

(b)

Fig. 8: The outer control loops: (a) Speed control (motoring mode); (b) DC voltage control (generating mode).

$$
I_{q, r e f}=\frac{T}{k_{t}}
$$

When the system is operating in generating mode, a DC voltage control is implemented as illustrated in Fig. 8(b). In this case, the PI controller generates a DC current reference, which is then saturated and converted into a torque reference $T_{r e f}$ by using Eq. (2).

$$
T_{\text {ref }}=I_{D C, r e f} \frac{V_{D C}}{\omega_{m}}
$$

Once the torque reference has been defined, the control algorithms follow the same structure, already described for the speed control.
Fig. 9(a) shows the control structure implemented for the DC voltage balancing control of the series connected NPCs. Based on the difference between the capacitor voltages $\mathrm{V}_{\mathrm{DC} 1}$ and $\mathrm{V}_{\mathrm{DC} 2}$, a PI controller generates an additional current reference, $\mathrm{I}_{\mathrm{q}, \mathrm{bal}}$.

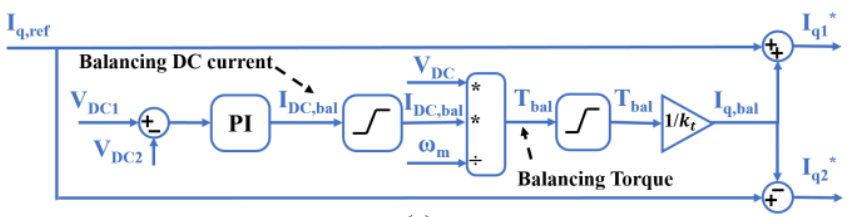

(a)

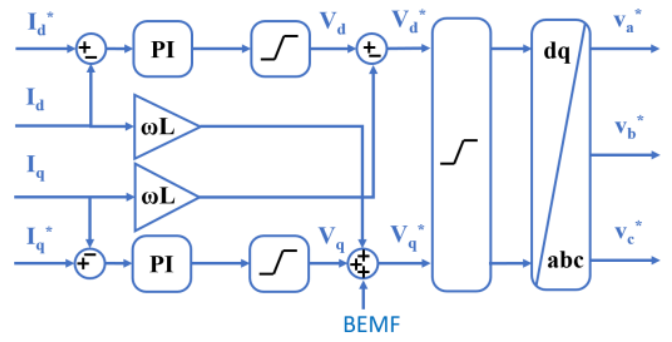

(b)

Fig. 9: The inner control loops: (a) series NPC DC voltage balancing control; (b) current control.

This is then summed/subtracted to/from the quadrature current set point of each NPC $\left(\mathrm{I}_{\mathrm{q} 1}{ }^{*}\right.$ and $\left.\mathrm{I}_{\mathrm{q} 2}{ }^{*}\right)$, to compensate for the voltage unbalance.

$$
\begin{gathered}
I_{q 1}^{*}+I_{q 2}^{*}=\left(I_{q, \text { ref }}+I_{q, \text { bal }}\right)+\left(I_{q, \text { ref }}-I_{q, \text { bal }}\right) \\
=2 I_{q, \text { ref }}
\end{gathered}
$$

It is important to highlight that this balancing control does not affect the dynamics of the outer loop, whilst maintaining the DC voltages balanced. A similar technique has already been applied in other series connected multilevel converters, such as Cascaded H-Bridge converters [41].

Finally, a standard $d-q$ current control with feed-forward compensation terms is implemented for each NPC converter as shown in Fig. 9 (b). In terms of modulation, a naturally sampled PWM strategy is used for each NPC converter in this application primarily for the benefits it can provide in terms of ease of implementation and computational burden on the control hardware. Additionally, a capacitor voltage balancing strategy is implemented within the modulation algorithm [40].

\section{POWER Losses AND EFFICIENCY of THE POWER CONVERTER}

A PLECS model has been implemented for the computation of the converter losses. The simulation calculates the conduction and switching losses as a function of the instantaneous current, voltage and junction temperature of each of the switching devices. Assuming the nominal operation for the generation unit is at $15000 \mathrm{rpm}$, with a DC link voltage of $3 \mathrm{kV}$, a total power of $4 \mathrm{MW}$, a power factor of 0.8 , and a switching frequency of $15 \mathrm{kHz}$, the simulated total losses of the converter are $\sim 58.5 \mathrm{~kW}$ ( $27.5 \mathrm{~kW}$ conduction, $31 \mathrm{~kW}$ switching) leading to a converter efficiency is $98.5 \%$.

The distribution of the losses within a power module are displayed in Fig. 10. Although the devices with the highest 
losses are the IGBTs 2,3 and the diodes 1,4 , the different thermal impedances mean that diodes 1 and 4 reach the highest junction temperature $(\mathrm{Tj})$. Their temperature reaches $130^{\circ} \mathrm{C}$, assuming a cold plate surface temperature of $100^{\circ} \mathrm{C}$. If the same converter is used to drive a machine (as a motor), at the same power, the efficiency will be slightly lower $98.4 \%$, with the total losses around $64 \mathrm{~kW}$.

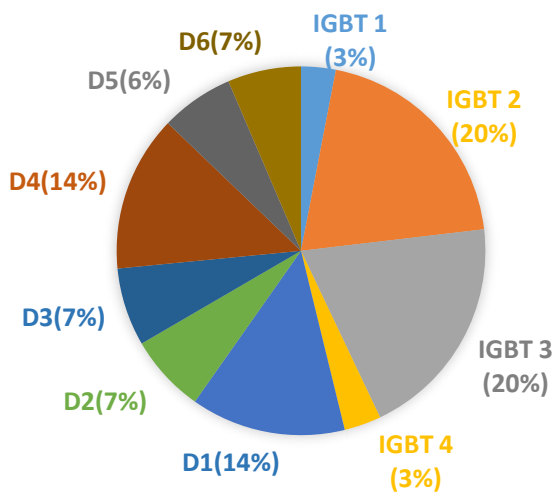

Fig. 10: Loss distribution inside the power module at the nominal condition in generating mode.

In this case, the distribution losses within a power module will be different: in this case, IGBTs 1 and 4 will be the devices with highest loss and highest junction temperature. Considering the same cold plate surface temperature of $100^{\circ} \mathrm{C}$, these IGBTs reach a junction temperature of $125^{\circ} \mathrm{C}$.

\section{EXPERIMENTAL RESULTS}

To validate the design of the converter, because of the limited DC link voltage available $(1.5 \mathrm{kV}$ instead of $3 \mathrm{kV})$, at the current test facility, the system has been tested using the arrangements shown in Fig. 11. The machine is not coupled to a load drive and both channels of the converter (BRAVO and ECHO) are connected to the same DC power supply. The power supply is capable of maintaining $1.5 \mathrm{kV}$, instead of the nominal value of $3 \mathrm{kV}$, and tests are performed using recirculating power operation of the system [42]-[44]. In Fig. 11 , power is recirculated by having the BRAVO converter in speed mode and ECHO in torque (or current) mode. In particular, BRAVO is motoring and ECHO is generating. With this mode of operation, the DC power supply only provides the system losses.

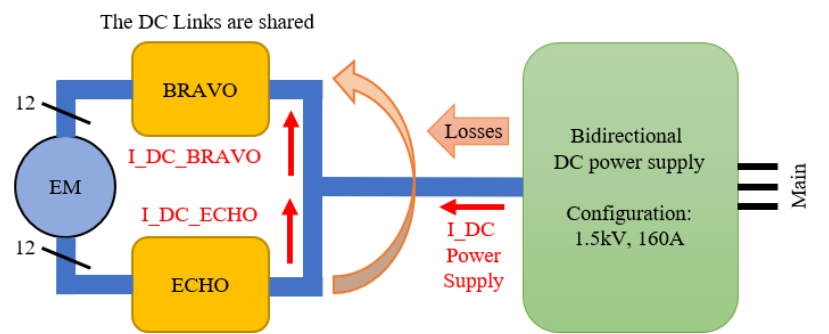

Figure 11: Test rig setup for recirculating power between $\mathrm{ECHO}$ and BRAVO.

In the following section several experimental measurements are presented, in Figs. 12-14 all data is recorded by the DSPs at a sampling rate of $66.6 \mu \mathrm{sec}$.
Fig. 12 shows the reference and measured speeds at the shaft from a $1 \mathrm{MW}$ test, where ECHO is controlling 300A (peak value). The oscillation is equal to $0.026 \%$ of the nominal speed value. This fluctuation does not affect the control operation and it can be neglected in practical operation. Due to the DC power supply voltage limit, the maximum speed of the machine is set to $7500 \mathrm{rpm}$. Fig. 13 illustrates the single capacitor voltages $(375 \mathrm{~V})$, series capacitor voltages $(750 \mathrm{~V})$, and DC-Link voltages $(1500 \mathrm{~V})$ for the BRAVO channel. This is equivalent for ECHO. During the tests, the main DC link was controlled by the external DC power supply. This responsible for the DC link oscillation which is also reflected onto the DC link voltage of the NPCs. The control for series voltage balance is working as designed and keeps the DC voltage of all the NPCs at the same level within a small tolerance. Fig. 13 also highlights the hysteresis voltage control for the internal capacitors of each NPC. The voltage oscillation is higher than expected at rated operation because the lower voltage for this test (half of the nominal value) results in much lower energy stored in the capacitors.

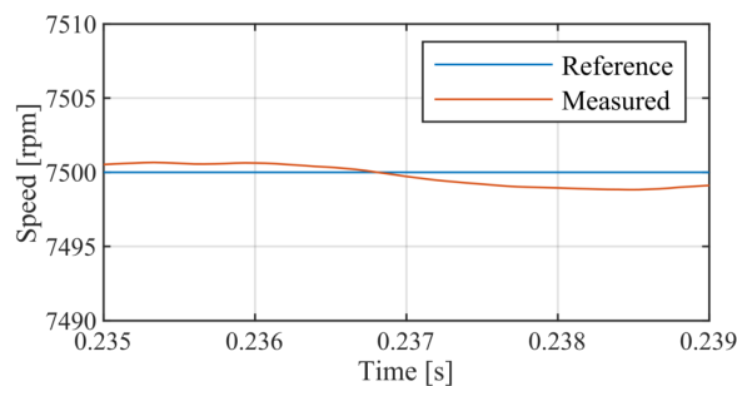

Fig. 12: Set-point and measured speed.

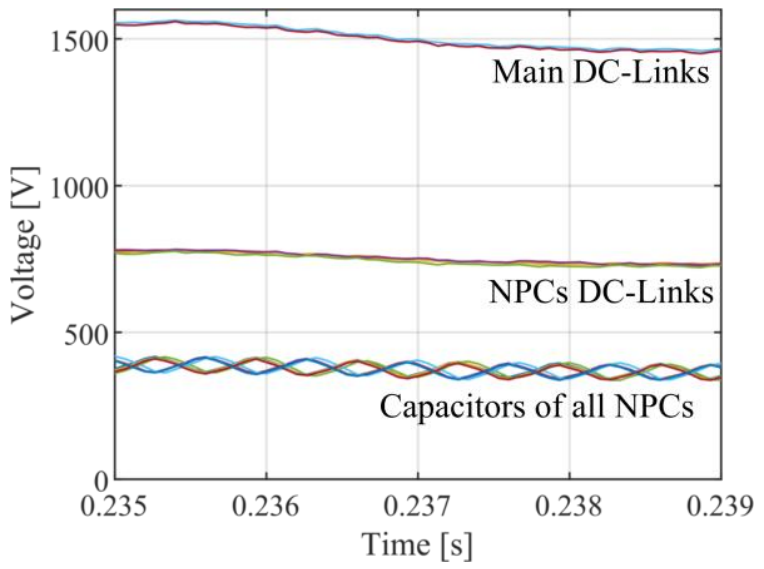

Fig. 13: Bravo converter: capacitor voltages (375V), DC-links NPCs (750V), and main DC-Link voltages (1500V).

In Fig. 14, the transformed direct and quadrature currents, of the fourth NPC of both BRAVO and ECHO, are shown. While BRAVO is controlling approximately $+300 \mathrm{~A}$ along the $\mathrm{q}$ axis, ECHO is keeping the speed of the shaft at 7500rpm by maintaining approximately $-300 \mathrm{~A}$ along its $\mathrm{q}$ axis. The low frequency ripple of the Iq currents is a consequence of the series DC voltage balancing algorithm, which is implemented to equalize the DC voltages of the series connected NPCs. Fig. 15 shows the measurements of the four phase currents while controlling $1 \mathrm{MW}$ of recirculating power. 
Two phases (B and C) of each channel, BRAVO and ECHO, are shown. In the figure a noticeable phase shift between the currents of the two systems is present. In fact, since one system is in monitoring mode while the other is in generation mode, a magnetic phase difference of 30 degrees is present, due to the winding distribution of the generator (see appendix A).

The experimental results achieved with the prototype converter and its related control algorithm agree with the expected design values. During the high-power tests, carried out in recirculating mode, the resulting drive system control was able to follow the reference. The obtained results can be considered as a first validation of the proposed high-power and high-voltage multi-level and multiphase drive architecture.

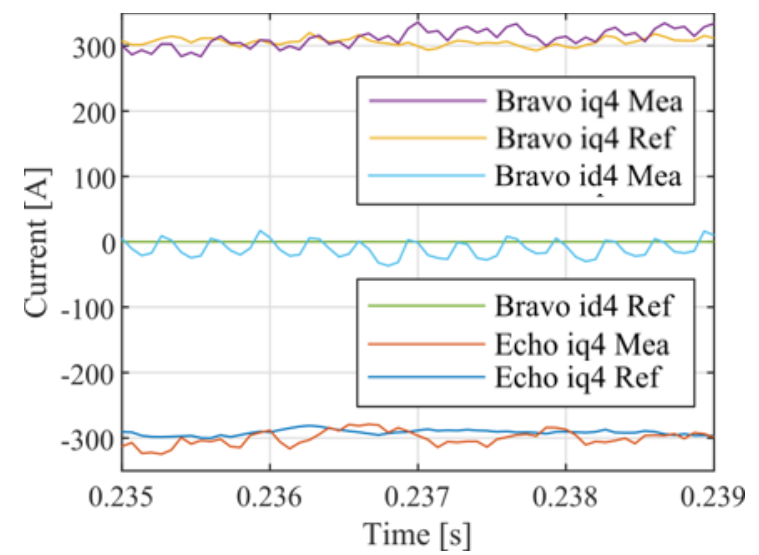

Fig. 14: Reference (Ref) and measured (Mea) iq and id currents of NPC4 from both BRAVO and ECHO converters.

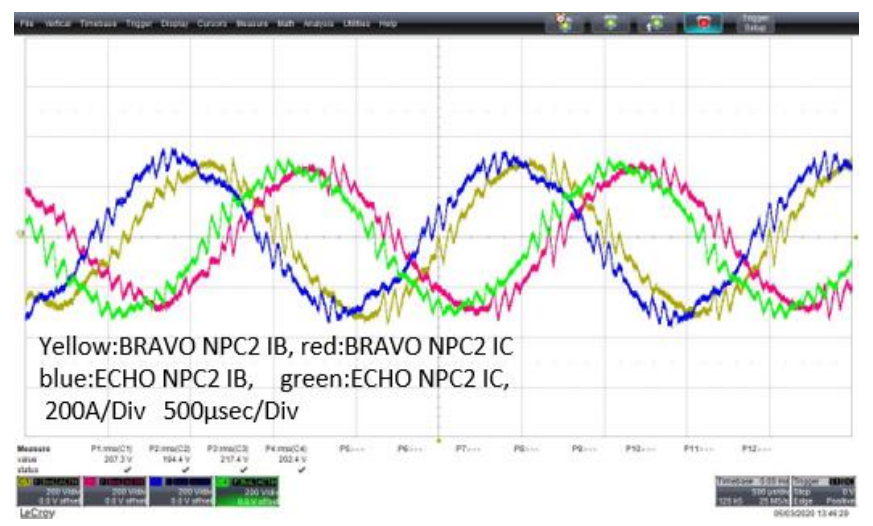

Fig. 15: Phase currents acquired by the oscilloscope.

During the same tests, with reference to Fig. 11, it was possible to assess the efficiency of the drive with the two channels (BRAVO and ECHO) in a "series" configuration. The power flows have been measured by acquiring the DC link voltage and the two IDC currents, of BRAVO and ECHO, respectively and feeding them to a power analyzer. Finally, the evaluation of the total losses has been carried out by measuring the output current of the power supply. The last measurement has also been useful to confirm the accuracy of the acquired data, as the sum of the three currents (or powers) flowing to the DC link connection point must be zero.
Fig. 16 shows the comparison of the efficiency resulting from simulations and experimental tests during recirculating power operation. Using a complete system model, which is including the machine, the validation has been performed at $7500 \mathrm{rpm}$, a DC link voltage of $1.5 \mathrm{kV}$, and a reference torque for the ECHO channel corresponding to a q-axis current (Iq_ref_ECHO) varying from 100Apk to 500Apk with steps of 100Apk. Analyzing the highest power test, the total losses of the series drive system are about $85 \mathrm{~kW}$, compared to the $84.3 \mathrm{~kW}$ obtained from the simulations. The split of the losses, according to the simulation results are $53.9 \mathrm{~kW}(64.7 \%$ of the total) in the machine. The remaining losses are split in the ratio15.8kW for BRAVO and $14.6 \mathrm{~kW}$ for $\mathrm{ECHO}$, i.e., the motoring and generating sides, respectively. The losses in BRAVO are higher because, as mention in the previous section, the efficiency is lower when motoring.

In order to show the remaining converter mode, an additional test is reported. The generator is connected to a prime mover operating at its nominal speed of $3000 \mathrm{rpm}$. The bidirectional DC power supply connected to the converter is controlled in current mode and operates as an electronic load. The voltage reference for the converter is $1.5 \mathrm{kV}$, and the current reference for the DC power supply is set to its maximum value of $160 \mathrm{~A}$, resulting in a total power of approximately $256 \mathrm{~kW}$.

Fig. 17 shows the BRAVO voltages: the two DC link voltages of the two layers, all voltages of the NPCS, all internal voltage of the NPC and the current of the DC link.

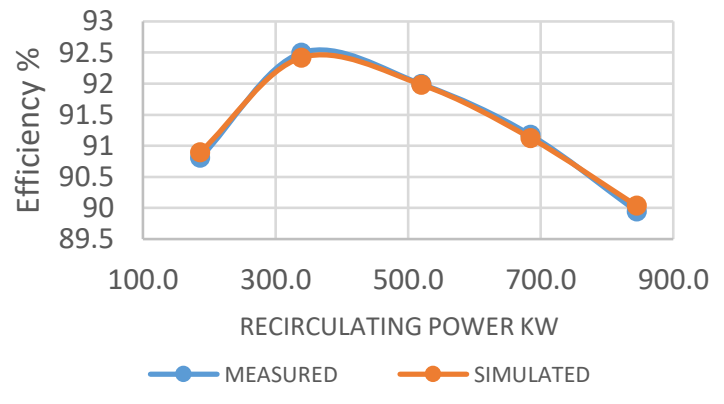

Fig. 16: Efficiency results: comparison between simulations and experimental measurements in recirculating power mode.

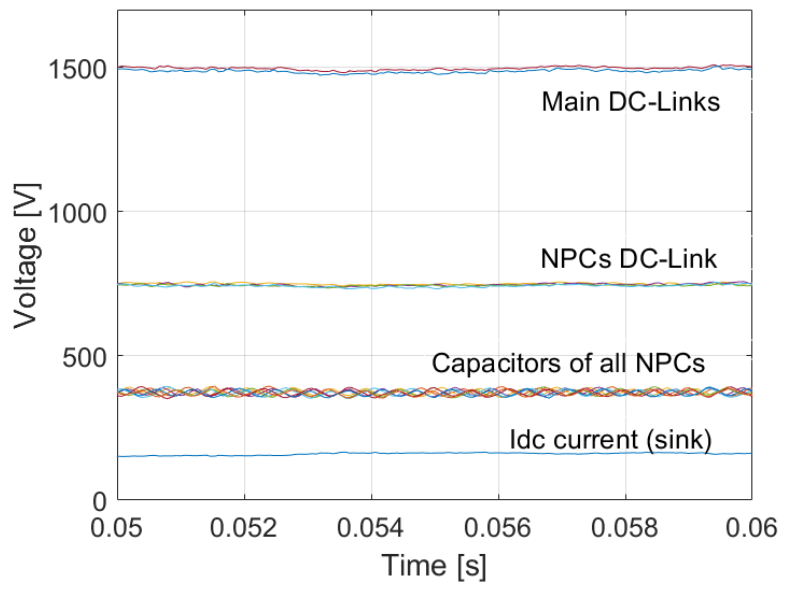

Fig. 17: Bravo system working in voltage mode, all relevant voltages and Idc current. 


\section{CONCLUSIONS}

In this paper, the research and development of a prototype 4MW (5MVA) medium voltage active rectifier (with two DClinks at $3 \mathrm{kV}$ ) to interface to a multi-winding 3-phase highspeed generator has been described. A generator with 8 independent 3-phase windings has been considered. The converter system adopted has been described and the development of the architecture concept to meet the topological requirements of the electrical machine and maximize the reliability of the system has been explained. The resulting structure uses NPC building blocks in cascade to achieve high voltage operation with relatively low voltage and high-speed devices. In this way the high frequency requirement imposed by the high-speed generator can be met. An experimental rig has been setup to perform a scaled down test up to $1 \mathrm{MW}$, adopting a recirculating power loop. The experimental results are in line with the expected performance and they validate the initial design and modelling. The outcomes of this work represent a step forward in terms of power density, voltage, power rating and frequency demand, with respect to the state of the art, and demonstrates the feasibility of a high power generator interface suitable for future high-speed, multimegawatt, medium-voltage series hybrid-electric aerospace systems.

\section{APPENDIX A - GENERATOR PARAMETERS}

The generator features a permanent magnet machine whose parameters are listed in Table III.

The machine has two sets of multiphase windings, one for each channel of the converter (BRAVO and ECHO). The two sets of windings are shifted by 30 electrical degrees. This phase shift is considered as an offset for the measurement of the rotor position in the control algorithm that manages the ECHO channel. Also, due to manufacturing aspects, the terminals of the winding belonging to the ECHO channel are placed on the opposite end-side of the electrical machine (i.e., shifted by additional 180 electrical degrees). This results in an equivalent shift of 150 electrical degrees between the two windings. This also explains the results shown in Fig. 15, where the opposite reference for the q-axis currents of the two channels has a phase shift of 30 electrical degrees (180-150).

TABLE III GENERATOR PARAMETERS

\begin{tabular}{ccc}
\hline \hline Parameter & Value & Unit \\
\hline Nominal Power & 4 & $\mathrm{MW}$ \\
Nominal speed & 15 & $\mathrm{krpm}$ \\
Nominal torque & $\sim 2.5$ & $\mathrm{kN}$ \\
Power factor & $\sim 0.8$ & $/$ \\
Pole pairs & 4 & $/$ \\
Electrical frequency & 1 & $\mathrm{kHz}$ \\
Number of phases & 24 & $/$ \\
Number of isolated 3-phase systems & 8 & $/$ \\
Number of magnetic phases & 6 & $/$ \\
Displacement between the winding sets & 30 & $\mathrm{el}$. deg \\
(electrical shift) & $(150)$ & \\
BEMF rms voltage & 404 & $\mathrm{~V}$
\end{tabular}

$\begin{array}{ccc}\text { BEMF THD } & 1.9 & \% \\ \text { Phase current } & 414 & \text { Arms } \\ \text { Self-leakage inductance } & 75 & \mu \mathrm{H} \\ \text { Phase resistance } & 12 & \mathrm{~m} \Omega\end{array}$

ACKNOWLEDGMENTS

The authors would like to thank Mykhaylo Filipenko and RollsRoyce Electric team for the great research collaboration. The authors would also like to thank John Hinchliffe (Senior technical manager), Kevin Last, Matthew Cooper and all the electrical and mechanical technical teams from the Power Electronics Machines and Control (PEMC) research group, Faculty of Engineering, The University of Nottingham. Their continued support with the planning, manufacturing, assembly of the prototypes and test rigs has been fundamental. The authors would like to thank Andrew Plummer and the mechanical team at Central Engineering Workshop (L2), Faculty of Engineering, The University of Nottingham, for their great technical support.

\section{REFERENCES}

[1] IATA. Technology Roadmap, 2018.

https://www.iata.org/en/publications/technology-roadmap/

[2] European Commission, Directorate-General for Mobility and Transport. 2015.https://ec.europa.eu/transport/sites/transport/files/modes/air/doc/flightpa th2050.pdf. DOI: $10.2777 / 15458$.

[3] European Commission, 2011. Flightpath 2050 Europe's Vision for Aviation, Report of the High Level Group on Aviation Research. DOI: $10.2777 / 50266$.

[4] K. L. Suder, "Overview of the NASA Environmentally Responsible Aviation Project's Propulsion Technology Portfolio," 48th AIAA/ASME/SAE/ASEE Jt. Propuls. Conf. Exhib., no. August, pp. 1-23, 2012.

[5] R. H. Jansen, C. Bowman, A. Jankovsky, R. Dyson, and J. Felder, "Overview of NASA electrified aircraft propulsion research for large subsonic transports", in Proc. AIAA Propuls. Energy, Atlanta, GA, USA, Jul. 2017, accessed: April. 2020. [Online].

Available: https://ntrs.nasa.gov/search.jsp?R=20170006235

[6] C. L. Bowman, J. L. Felder and T. V. Marien, "Turbo- and HybridElectrified Aircraft Propulsion Concepts for Commercial Transport", 2018 AIAA/IEEE Electric Aircraft Technologies Symposium (EATS), Cincinnati, OH, USA, 2018, pp. 1-8.

[7] ACARE. Strategic Research and Innovation Agenda (SRIA), 2017. http://www.acare4europe.org/sites/acare4europe.org/files/document/ACAREStrategic-Research-InnovationVolume-1.pdf

[8] D. F. Finger, C. Braun and C. Bil, "Case Studies in Initial Sizing for HybridElectric General Aviation Aircraft," 2018 AIAA/IEEE Electric Aircraft Technologies Symposium (EATS), Cincinnati, OH, 2018, pp. 1-22.

[9] R. Del Rosario, "A future with hybrid electric propulsion systems: A NASA perspective," in Proceedings of Turbine Engine Technology Symposium (TETS), Sept. 2014.

[10] Airbus. Airbus, Rolls-Royce, and Siemens team up for electric future Partnership launches E-Fan X hybrid-electric flight demonstrator, 2017. http://www.airbus.com/newsroom/press-releases/en/2017/11/airbus--rollsroyce--andsiemens-team-up-for-electric-future-par.html\#media-list-imageimage-all_ml_0-2.

[11] Siemens. Airbus, Rolls-Royce, and Siemens to Develop Flying Demonstrator, 2017. https://www.siemens.com/innovation/en/home/picturesof-the-future/mobility-and-motors/the-future-of-mobility-efan-x.html

[12] Clean Energy Wire. Emission-free aviation is technically feasible - DLR Researcher, 2018. https://www.cleanenergywire.org/news/emission-freeaviation-technically-feasible-dlr-researcher

[13] Zunum Aero. 2018. https://www.aerospacetechnology.com/projects/zunum-aero-hybrid-electric-aircraft/

[14] W. Cao, B. C. Mecrow, G. J. Atkinson, J. W. Bennett and D. J. Atkinson, "Overview of Electric Motor Technologies Used for More Electric Aircraft (MEA)", in IEEE Transactions on Industrial Electronics, vol. 59, no. 9, pp. 3523-3531, Sept. 2012. 
[15] G. Sulligoi, A. Tessarolo, V. Benucci, A. Millerani Trapani, M. Baret and F. Luise, "Shipboard Power Generation: Design and Development of a Medium-Voltage dc Generation System", in IEEE Industry Applications Magazine, vol. 19, no. 4, pp. 47-55, July-A.

[16] V. Madonna, P. Giangrande and M. Galea, "Electrical Power Generation in Aircraft: Review, Challenges, and Opportunities", in IEEE Transactions on Transportation Electrification, vol. 4, no. 3, pp. 646-659, Sept. 2018.

[17] S. Bernet, "Recent developments of high power converters for industry and traction applications", in IEEE Transactions on Power Electronics, vol. 15, no. 6, pp. 1102-1117, Nov. 2000.

[18] B. K. Bose, "Power Electronics and Motor Drives Recent Progress and Perspective", in IEEE Transactions on Industrial Electronics, vol. 56, no. 2, pp. 581-588, Feb. 2009.

[19] H. Polinder, F. F. A. van der Pijl, G. de Vilder and P. J. Tavner, "Comparison of direct-drive and geared generator concepts for wind turbines", in IEEE Transactions on Energy Conversion, vol. 21, no. 3, pp. 725-733, Sept. 2006.

[20] D. Golovanov, L. Papini, D. Gerada, Z. Xu and C. Gerada, "Multidomain Optimization of High-Power-Density PM Electrical Machines for System Architecture Selection," in IEEE Transactions on Industrial Electronics, vol. 65, no. 7, pp. 5302-5312, July 2018, doi: 10.1109/TIE.2017.2772188.

[21] M. Darijevic, M. Jones, O. Dordevic and E. Levi, "Decoupled PWM Control of a Dual-Inverter Four-Level Five-Phase Drive", in IEEE Transactions on Power Electronics, vol. 32, no. 5, pp. 3719-3730, May 2017.

[22] A. Tessarolo, G. Zocco and C. Tonello, "Design and Testing of a 45-MW $100-\mathrm{Hz}$ Quadruple-Star Synchronous Motor for a Liquefied Natural Gas Turbo-Compressor Drive", in IEEE Transactions on Industry Applications, vol. 47, no. 3, pp. 1210-1219, May-June

[23] L. Parsa and H. A. Toliyat, "Five-phase permanent magnet motor drives for ship propulsion applications", in IEEE Electric Ship Technologies Symposium, 2005, pp. 371-378.

[24] J. Dai, S. W. Nam, M. Pande, and G. Esmaeili, "Medium-Voltage CurrentSource Converter Drives for Marine Propulsion System Using a Dual-Winding Synchronous Machine", IEEE Transactions on Industry Applications, vol. 50, pp. 3971-3976, 2014.

[25] C. Bassi, A. Tessarolo, R. Menis, and G. Sulligoi, "Analysis of different system design solutions for a high-power ship propulsion synchronous motor drive with multiple PWM converters", Electrical Systems for Aircraft, Railway and Ship Propulsion, Bologna, 2010, pp. 1-6.

[26] E. Levi, "Advances in Converter Control and Innovative Exploitation of Additional Degrees of Freedom for Multiphase Machines", in IEEE Transactions on Industrial Electronics, vol. 63, no. 1, pp. 433-448, Jan. 2016. [27] L. Ó, J. Alvarez, J. Doval-Gandoy, and F. D. Freijedo, "Multilevel Multiphase Space Vector PWM Algorithm", IEEE Transactions on Industrial Electronics, vol. 55, pp. 1933-1942, 2008.

[28] E. Levi, I. N. W. Satiawan, N. Bodo, and M. Jones, "A Space-Vector Modulation Scheme for Multilevel Open-End Winding Five-Phase Drives", IEEE Transactions on Energy Conversion, vol. 27, pp. 1-10, 2012.

[29] Rodri'guez, S. Bernet, B. Wu, J. Pontt, and S. Kouro, "Multilevel voltagesource-converter topologies for industrial medium-voltage drives", IEEE Trans. Ind. Electron., vol. 54, no. 6, pp. 2930-2945, Dec. 2007.

[30] S. Bozhko et al., "Development of Aircraft Electric Starter-Generator System Based on Active Rectification Technology," in IEEE Transactions on Transportation Electrification, vol. 4, no. 4, pp. 985-996, Dec. 2018, doi: 10.1109/TTE.2018.2863031.

[31] F. Crescimbini, A. Lidozzi, and L. Solero, "High-Speed generator and multilevel converter for energy recovery in automotive systems," IEEE Trans. Ind. Electron., vol. 59, no. 6, pp. 2678-2688, 2012.

[32] S. Mukherjee, S. Kumar Giri, S. Kundu, and S. Banerjee, "A generalized discontinuous PWM scheme for three-level NPC traction inverter with minimum switching loss for electric vehicles," IEEE Trans. Ind. Appl., vol. 55, no. 1, pp. 516-528, 2019.

[33] S. Mukherjee, S. K. Giri, and S. Banerjee, "A flexible discontinuous modulation scheme with hybrid capacitor voltage balancing strategy for threelevel NPC traction inverter," IEEE Trans. Ind. Electron., vol. 66, no. 5, pp. 3333-3343, 2019.

[34] S. Castagno, R. D. Curry and E. Loree, "Analysis and Comparison of a Fast Turn-On Series IGBT Stack and High-Voltage-Rated Commercial IGBTS," in IEEE Transactions on Plasma Science, vol. 34, no. 5, pp. 16921696, Oct. 2006.

[35] M. M. Swamy, J. Kang and K. Shirabe, "Power Loss, System Efficiency, and Leakage Current Comparison Between Si IGBT VFD and SiC FET VFD With Various Filtering Options," in IEEE Transactions on Industry Applications, vol. 51, no. 5, pp. 3858-3866, Sept.- Oct. 2015.
[36] D. Zhang, J. He and D. Pan, "A Megawatt-Scale Medium-Voltage HighEfficiency High Power Density "SiC+Si" Hybrid Three-Level ANPC Inverter for Aircraft Hybrid-Electric Propulsion Systems," in IEEE Transactions on Industry Applications, vol. 55, no. 6, pp. 5971-5980, Nov.-Dec. 2019, doi: 10.1109/TIA.2019.2933513.

[37] H. Zhang, J. Imaoka, M. Noah, Y. Ishikura and M. Yamamoto, "Study on the Imbalanced Voltage of Series-connected Active Power Semiconductor Devices in Power Conversion Systems," 2019 IEEE Workshop on Wide Bandgap Power Devices and Applications in Asia (WiPDA Asia), Taipei, Taiwan, 2019, pp. 1-4.

[38] A. Trentin, L. Empringham, L. de Lillo, P. Zanchetta, P. Wheeler and J. Clare, "Experimental Efficiency Comparison Between a Direct Matrix Converter and an Indirect Matrix Converter Using Both Si IGBTs and SiC mosfets," in IEEE Transactions on Industry Applications, vol. 52, no. 5, pp. 4135-4145, Sept.-Oct. 2016, doi: 10.1109/TIA.2016.2573752.

[39] R. De Doncker, D. Pulle, and A. Veltman, Advanced Electrical Drives: Analysis, Modeling, Control, ser. Power Systems. Springer Netherlands, 2010. [40] J. Pou, J. Zaragoza, S. Ceballos, M. Saeedifard and D. Boroyevich, "A Carrier-Based PWM Strategy With Zero-Sequence Voltage Injection for a Three-Level Neutral-Point-Clamped Converter," in IEEE Transactions on Power Electronics, vol. 27, no. 2, pp. 642-651, Feb. 2012.

[41] H. Q. S. Dang et al., "Advanced integration of multilevel converters into power system,” IEEE Annu. Conf. Ind. Electron., no. 1, pp. 3188-3194, Nov. 2008.

[42] F. Luise, S. Pieri, M. Mezzarobba, and A. Tessarolo, "Regenerative Testing of a Concentrated-Winding Permanent-Magnet Synchronous Machine for Offshore Wind Generation-Part I: Test Concept and Analysis," IEEE Trans. Ind. Appl., vol. 48, no. 6, pp. 1779-1790, 2012.

[43] F. Luise, S. Pieri, M. Mezzarobba, and A. Tessarolo, "Regenerative Testing of a Concentrated-Winding Permanent-Magnet Synchronous Machine for Offshore Wind Generation-Part II: Test Implementation and Results," IEEE Trans. Ind. Appl., vol. 48, no. 6, pp. 1791-1796, 2012.

[44] A. A. Abduallah, O. Dordevic, M. Jones and E. Levi, "Regenerative Test for Multiple Three-Phase Machines With Even Number of Neutral Points," in IEEE Transactions on Industrial Electronics, vol. 67, no. 3, pp. 1684-1694, March 2020.

[45] D. A. Grant and R. Seidner, "Ratio changing in pulse-width-modulated inverters," in IEE Proceedings B - Electric Power Applications, vol. 128, no. 5, pp. 243-248, September 1981, doi: 10.1049/ip-b.1981.0040.

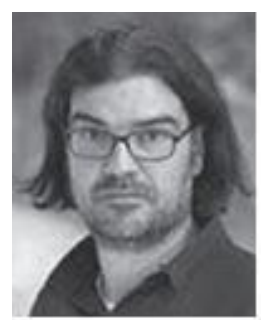

Andrew Trentin received the "Laurea" Master's degree and $\mathrm{Ph} . \mathrm{D}$. degree in electrical engineering from the University of Bologna, Bologna, Italy, in 2001 and 2005, respectively.

Since 2005, he has been a Research Fellow in the Power Electronics, Machines and Control Research Group, at The University of Nottingham, UK, and promoted to Senior Research Fellow in 2012. His research interests are power electronics and electrical drives for different applications and in direct ac/ac

matrix converters.

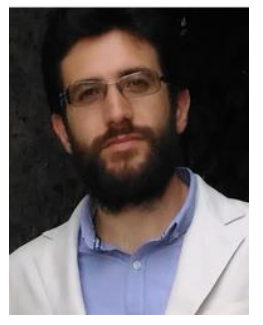

Giacomo Sala received the B. Sc. in Power Engineering in 2012 from the University of Bologna, Italy, the M. Sc. degree with honors in Electrical Engineering in 2014 and the Ph.D. in Electrical Machines and Drives in 2018, from the same university. He has been a research associate/fellow until 2019 in the Power Electronics, Machines and Control Group, Dept. of Electrical and Electronic Engineering, The University of Nottingham, UK. In 2019 he joined the Dept. of Electrical, Electronic, and Information Engineering "G. Marconi" of the University of Bologna, where he is currently an assistant professor. His research interests include design, modelling and control of multiphase electrical machines, fault tolerant controls and fault diagnosis of electric drives. 


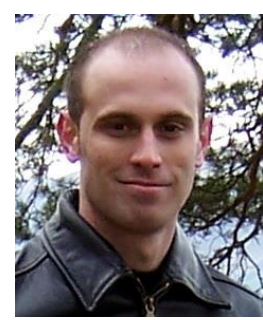

Luca Tarisciotti (S'12-M'15) received the Master's degree in Electronic Engineering from The University of Rome "Tor Vergata" in 2009 and his Ph.D. degree in Electrical and Electronic Engineering from the PEMC group, University of Nottingham in 2015. In the same year he became Research Fellow at the University of Nottingham, UK, until 2018. He is currently working as Assistant Professor at the University Andres Bello, Santiago, Chile. His research interests includes Matrix converters, DC/DC converters, Multilevel converters, Advanced modulation schemes, and Advanced power electronics converter control.

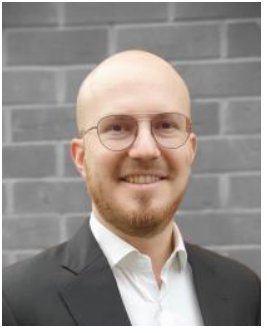

Alessandro Galassini (S'13-M'20) received the master's degree in mechatronic engineering from the University of Modena and Reggio Emilia, Reggio Emilia, Italy, in 2012, and the Ph.D. degree in power sharing for multi-three-phase electrical machines from the University of Nottingham, Nottingham, UK, in 2017. He is currently a Research Fellow with the Power Electronics, Machines and Control Group, The University of Nottingham. His research interests include control of electrical drives for future

transportation systems.

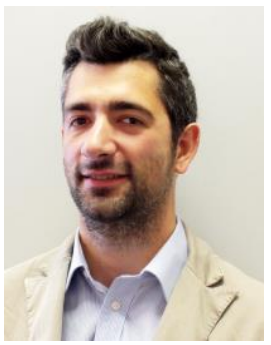

Michele Degano (M'15) received his Master's degree in Electrical Engineering from the University of Trieste, Italy, in 2011, and his Ph.D. degree in Industrial Engineering from the University of Padova, Italy, in 2015. Between 2014 and 2016, he was a post-doctoral researcher at The University of Nottingham, UK, where he joined the Power Electronics, Machines and Control (PEMC) Research Group. In 2016 he was appointed Assistant Professor in Advanced Electrical Machines, at The University of Nottingham, UK. He was promoted Associate Professor in 2020. His main research focuses on electrical machines and drives for industrial, automotive, railway and aerospace applications, ranging from small to large power. He is currently the PEMC Director of Industrial Liaison leading research projects for the development of hybrid electric aerospace platforms and electric transports.

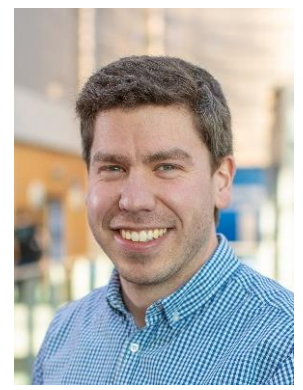

Peter H. Connor received an M.Eng. and Ph.D. from the Department of Mechanical, Materials and Manufacturing Engineering Department, University of Nottingham, UK, in 2009 and 2014, respectively. He is a Senior Research Fellow in the Power Electronics, Machines and Control Research Group in the Faculty of Engineering at the University of Nottingham. His research interests are mechanical design and thermal management of electrical machines for industrial power generation and high-speed, high powerdensity traction and aerospace applications.

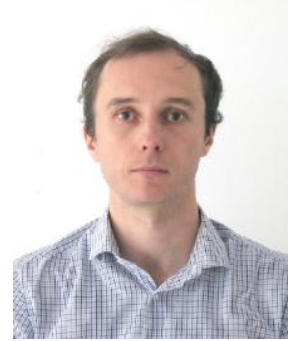

Dmitry Golovanov received the Ph.D. degree in superconducting electrical machines from Moscow Aviation Institute, Moscow, Russia, in 2011.,He has an experience of working in industry as a Researcher in VNIIEM Corporation JSC, Russia, in the field of design of electrical machines and in Samsung SDI, South Korea, in the field of Li-ion batteries. He is currently a Research Fellow in the University of Nottingham, Nottingham, UK. His main research interests include high power density electric machines for aerospace and automotive industry application, and superconducting electrical machines.

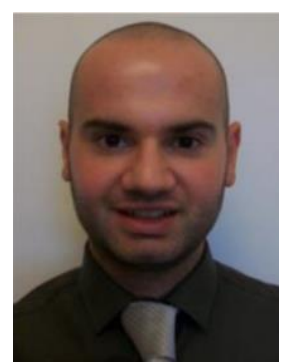

David Gerada received the Ph.D. degree in highspeed electrical machines from University of Nottingham, Nottingham, U.K., in 2012. From 2007 to 2016, he was with the R\&D Department at Cummins, Stamford, U.K., first as an Electromagnetic Design Engineer (2007- 2012), and then as a Senior Electromagnetic Design Engineer and Innovation Leader (2012- 2016). At Cummins, he pioneered the design and development of high-speed electrical machines, transforming a challenging technology into a reliable one suitable for the transportation market, while establishing industry-wide-used metrics for such machinery. In 2016, he joined the University of Nottingham where he is currently a Principal Research Fellow, responsible for developing state-of-theart electrical machines for future transportation which push existing technology boundaries, while propelling the new technologies to higher technology readiness levels. Dr. Gerada is a Chartered Engineer in the U.K. and a member of the Institution of Engineering and Technology.

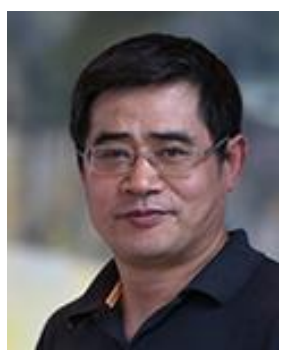

Zeyuan Xu, IEEE member, received his $\mathrm{PhD}$ degree in mechanical engineering from the University of Manchester, Manchester, U.K. in 2002. He subsequently worked as a Research Fellow at UMIST, Brunel University, and the University of Nottingham. He is currently a Senior Research Fellow in thermo-mechanical design of high speed electrical machines within the PEMC group at the University of Nottingham, Nottingham, U.K.

His main research interests include turbulent thermo-fluid flow, heat transfer enhancement, thermal management of advanced electrical machines and power electronics, electrical machine structure analysis, rotor dynamics analysis and mechanical design.

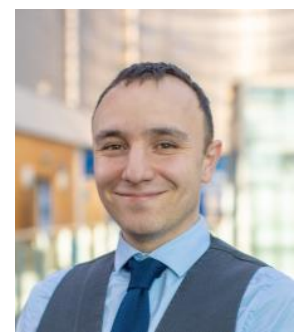

Antonino La Rocca received his Ph.D. from the Department of Mechanical, Materials and Manufacturing Engineering Department, University of Nottingham, UK, in 2016. He is a Research Fellow in the Fluids and Thermal Engineering Research Group and the Power Electronics, Machines and Control Research Group in the Faculty of Engineering at the University of Nottingham. His research field is the thermo-mechanical modelling and design of high speed and high power dense electrical machines and power electronics designs for advanced generation and propulsion systems by the use of Lumped Parameters Thermal networks (LPTN) and Computational Fluid Dynamics (CFD) and FEA.

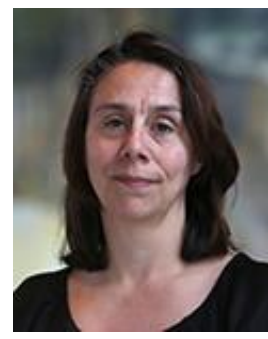

Carol N. Eastwick received his Master's degree in Electrical Carol N. Eastwick received her BEng and $\mathrm{PhD}$ in Mechanical Engineering in 1990 (Imperial College) and 1995 (University of Nottingham). She is a Professor at the University of Nottingham and Head of the Gas Turbine Transmissions Research Centre. Her research interests include two phase fluid flows associated with solid combustion and cooling/thermal management and she has worked on modelling and experimental investigations of thermofluids associated with rotating machinery for over twenty years.

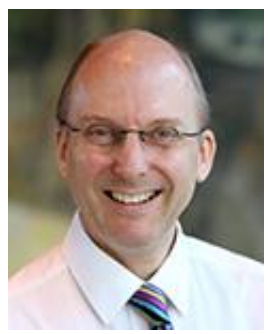

Stephen J. Pickering obtained a BSc in Mechanical Engineering in 1979 and a $\mathrm{PhD}$ in Mechanical Engineering in 1984 both from the University of Nottingham. Following several years in industry he was appointed as a lecturer at the University of Nottingham in 1988 where he currently holds the Hives Chair in Mechanical Engineering. He has extensive research interests in the area of thermofluids and has undertaken research into thermal management of electric machines and power electronics systems for over 25 years. 


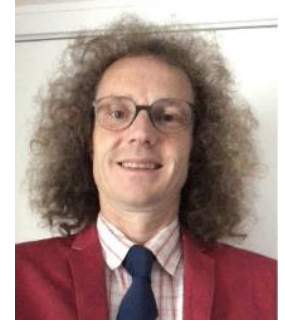

Prof Pat Wheeler received his BEng [Hons] degree in 1990 from the University of Bristol, UK. He received his $\mathrm{PhD}$ degree in Electrical Engineering for his work on Matrix Converters from the University of Bristol, UK in 1994. In 1993 he moved to the University of Nottingham and worked as a research assistant in the Department of Electrical and Electronic Engineering. In 1996 he became a Lecturer in the Power Electronics, Machines and Control Group at the University of

Nottingham, UK. Since January 2008 he has been a Full Professor in the same research group.

He was Head of the Department of Electrical and Electronic Engineering at the University of Nottingham from 2015 to 2018 . He is currently the Head of the Power Electronics, Machines and Control Research Group, Global Director of the University of Nottingham's Institute of Aerosapce Technology and is the Li Dak Sum Chair Professor in Electrical and Aerospace Engineering. He is a member of the IEEE PELs AdCom and was an IEEE PELs Distinguished Lecturer from 2013 to 2017. He has published 750 academic publications in leading international conferences and journals.

Prof Pat Wheeler was involved in the writing of the rules for TTXGP, the first electric superbike Grandprix, in 2009. Since then he has been involved in the regulations for electric superbike racing as well as founding the University of Nottingham's Electric Superbike team, which has finished on the podium in 3 out of the last 4 years as well as being the European Champions two years in a row. He has also been involved in Solar Cars, initially as the international observer for the inaugural Chilean Solar Challenge in 2010.

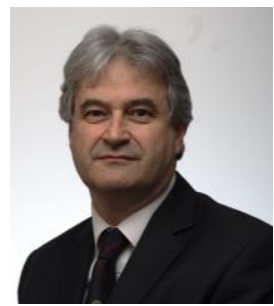

Jon Clare (M'90-SM'04) was born in Bristol, UK, in 1957. He received the $\mathrm{BSc}$ and $\mathrm{PhD}$. degrees in electrical engineering from the University of Bristol, UK, in 1979 and 1990, respectively. From 1984 to 1990, he was a Research Assistant and Lecturer with the University of Bristol, where he was involved in teaching and research on power electronic systems. Since 1990, he has been with the Faculty of Engineering at the University of Nottingham, UK. $\mathrm{He}$ is currently Professor of Power Electronics and is the Head of the Electrical and Electronic Engineering Department. He is a member of the Power Electronics, Machines and Control Research Group at Nottingham. His research interests are in power-electronic converters and their applications and control. Jon Clare is a Fellow of the IET and the recipient of a Royal Society Wolfson Research Merit Award.

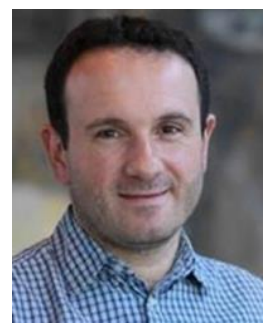

Chris Gerada (SM'12) is an Associate Pro-ViceChancellor for Industrial Strategy and Impact and Professor of Electrical Machines. His principal research interest lies in electromagnetic energy conversion in electrical machines and drives, focusing mainly on transport electrification. He has secured over $£ 20 \mathrm{M}$ of funding through major industrial, European and UK grants and authored more than 350 referred publications. He received the $\mathrm{Ph} . \mathrm{D}$. degree in numerical modelling of electrical machines from The University of Nottingham, Nottingham, U.K., in 2005. He subsequently worked as a Researcher with The University of Nottingham on high-performance electrical drives and on the design and modelling of electromagnetic actuators for aerospace applications. In 2008, he was appointed as a Lecturer in electrical machines; in 2011, as an Associate Professor; and in 2013, as a Professor at The University of Nottingham. He was awarded a Research Chair from the Royal Academy of Engineering in 2013. Prof. Gerada served as an Associate Editor for the IEEE Transactions on Industry Applications and is the past Chair of the IEEE IES Electrical Machines Committee. 